\title{
Erratum to: The Critical Rainfall Characteristics for Torrents and Debris Flows in the Wenchuan Earthquake Stricken Area
}

\author{
CHEN Ningsheng a,b , YANG Chenglin ${ }^{\text {a,b }}$, ZHOU Wei ${ }^{\text {a,b }}$, HU Guisheng a,b, LI Huan ${ }^{\text {c, }}$ \\ and David Hand \\ a Key Lab of Mountain Hazards and Surface Processes, Chinese Academy of Sciences, Chengdu, China,610o41 \\ $b$ Institute of Mountain Hazards and Environment, Chinese Academy of Sciences, Chengdu, China, 610041 \\ c College of Water Resource \& Hydropower of SCU, Chengdu, China, 610065 \\ d Department of Civil Engineering, University of Bristol, UK
}

(C) Science Press and Institute of Mountain Hazards and Environment, CAS and Springer-Verlag Berlin Heidelberg 2010

Erratum to: J. Mt. Sci.

DOI: $10.1007 / \mathbf{s} 11629-009-1064-9$

In the online version of the article the last name of the last author is misspelled. The correct spelling is "Han". 